\title{
Cleidocranial dysplasia: a case report
}

\section{Displasia cleidocraneal: reporte de un caso}

\section{Olga Medina $^{\mathrm{a}, \mathrm{c}}$, Nelson Muñoz ${ }^{\mathrm{a}, \mathrm{b}}$, Carlos Moneriz $^{\mathrm{d}}$}

aNaval Hospital, Cartagena (Colombia)

${ }^{b}$ Department of Pediatrics. Faculty of Medicine, University of Cartagena (Colombia)

'Department of Pediatrics. Faculty of Medicine, University of Sinú Elías Bechara Zainum. Cartagena Colombia)

${ }^{\mathrm{d}}$ Group of Biochemistry and Disease. Faculty of Medicine, University of Cartagena (Colombia)

Received: 18-7-2016; Accepted: 27-9-2016

\begin{abstract}
Introduction: Cleidocraneal dysplasia (CCD) is a rare skeletal autosomal dominant syndrome characterized by dental anomalies and bone abnormalities. These clinical manifestations do not require treatment in most cases. The disease is caused by mutation in the gene RUNX2 (CBAF1), located on the short arm of chromosome 6. Objective: To report a case of CCD and perform a literature review focused on clinical manifestations and diagnosis. Case report: A 3 year old patient, who was clinically diagnosed with CCD since birth. The patient showed incomplete development of cranial bones, bell-shaped thorax, adequate dentition and presence of clavicles. Molecular analysis reported that the patient is carrying the pathogenic variant c. $674 \mathrm{G}>\mathrm{A}$ in the RUNX2 gene, confirming the diagnosis. Conclusions: The CCD is a rare condition, with special clinical features. It is important to establish early diagnosis in these patients in order to offer a better quality of life, and if necessary, appropriate treatment.
\end{abstract}

\section{Keywords:}

Cleidocranial dysplasia, RUNX2,

Autosomal dominant, Mutation 


\section{Introduction}

Cleidocranial dysplasia (CCD) is a rare autosomal dominant skeletal syndrome $(1: 1,000,000)$ with almost a complete genetic penetrance with a variable clinical expression ${ }^{1,2}$, caused by a mutation in the RUNX2 (Runt-related transcription factor 2) ${ }^{1}$. This gene encodes the synthesis of RUNX2 protein, also called CBFA1 (core-binding factor subunit alpha-1), which takes part of the osteoblastic differentiation and the skeletal morphogenesis ${ }^{1,3}$. The CCD can be present as a mutation in $60 \%$ of the cases, in a $10 \%$ it can be present as deletion, and in the remaining percentage of patients, no mutation of the gene has been found, which it is assumed that there is heterogenecity of loci, involving another genes.

The CCD is characterized by frontal and parietal prominence, brachycephaly, late closure of the cranial sutures, hypoplasia or clavicle aplasia (which it does not occur in all patients) and multiple dental anomalies $^{3,5-12}$. All these features tend to be vary, even among the members of the same family. The CCD can be detected from an early age, even during the prenatal period through ultrasound findings ${ }^{13,14}$.

Patients with CCD are smaller than their unaffected siblings and they are more likely to have skeletal and orthopedic problems, such as flat feet, valgus and scoliosis $^{4-6}$. Neuro-maturational development and life expectancy are normal, with an adult height of $1.65 \mathrm{~cm}$ in men and $1.56 \mathrm{~cm}$ in women. The main complications are: recurrent acute otitis media $(62 \%)$ and hearing loss $(38 \%)^{15}$.

Skeletal dysplasias are genetic diseases of chronic evolution and they require multidisciplinary treatment, focused on measures of symptomatic support, but also preventive and preemptive ${ }^{1,9}$.

This article reports the case of a 3 year old child diagnosed with CCD at the moment of birth. The objective is to give the alert to the health team about the importance of establishing a timely diagnosis in these patients in order to offer them a better quality of life, and an appropriate treatment.The diagnosis was support by clinical, radiological and molecular elements, in this clinical case. The review of the medical history was approved by the Cartagena Naval Hospital of the City of Cartagena (Colombia), in accordance with the Resolution 008430 in 1993 and the Resolution 2378 in 2008 of the Ministry of Health and Social Protection.

\section{Clinical Case}

Child of 3 years of age, controlled from the moment of his birth in the Naval Hospital of Cartagena in the city of Cartagena de Indias (Colombia). He is the son of a 22-year-old mother, first pregnancy (contro- lled), born by natural birth and without complications. Gestation of 39 weeks, birth weight of 3320 g; Length of $49 \mathrm{~cm}$; Cephalic perimeter of $33 \mathrm{~cm}$; Apgar 8 in the first minute and 10 at 5 minutes; Blood group B, Rh positive. Family history does not report other family members with similar phenotypic or with low height characteristics.

In the physical examination of the newborn, there was an absence of palpable caraneous bones, a broad nasal bridge with ocular hypertelorism. The thorax was normal, palpable clavicles and no deformities were evident. Examination of abdomen and limbs was normal. The neurological examination described tone, strength and sensibility conserved, with archaic reflexes.

The skull radiograph showed incomplete development of the cranial bones (Figure 1A), and the diagnosis of CCD was considered. Computed tomography (CT) performed one week after birth showed no calcification of the frontal and parietal bones, and these structures remained in the membranous state.

The brain CT with three-dimensional reconstruction performed at one month of life reported an alteration in the morphology of the cranial vault due to the absence of calcification of the membranous structures of the frontal, parietal and temporal bones, which belongs to a greater amplitude of the cranial sutures and of the fontanelles (figure 1B). This confirmed the absence of the process of calcification of the membranous structures of the cranial bones ${ }^{16}$. At the third month of birth, an MRI of the central nervous system reconfirmed the absence of ossification of the frontal and parietal bones. In the same period, the chest X-ray showed a normal cardiotymic silhouette, with no opacities in lung fields, with normal costal arches, with less development of the lateral third of clavicles and with somewhat hypoplastic scapula (Figure 2A). In the $\mathrm{x}$ ray of the hips at the fourth month of after his birth, there was no ossification of the pubis, associated with hypoplasia of iliac bones (figure 2B).

At two years of age, skull and dorsal spine radiographs reported cranial vault asymmetry, with suture diastasis and open anterior fontanelle. Scoliosis, normal bone density, height and shape of normal vertebral bodies and preserved intervertebral spaces were noticed in the dorsal spine.

The cytogenetic study in peripheral blood showed karyotype 46, XY (50 metaphases analyzed, 600 bands) without numerical or structural alterations.

In the physical examination at the age of 3 years, the patient was presented with a weight of $13 \mathrm{~kg}(0-1$ $\mathrm{DE})$, size: $93 \mathrm{~cm}$ (0-1 DE), bifid skull, wide nasal bridge (Figure 3A), bone depression at the level of the frontal bone that can only be seen in the frontal but not in profile photos (Figure 3B, C and D), without the presence of meiofacial hypoplasia (Figure 3A). No dental alte- 


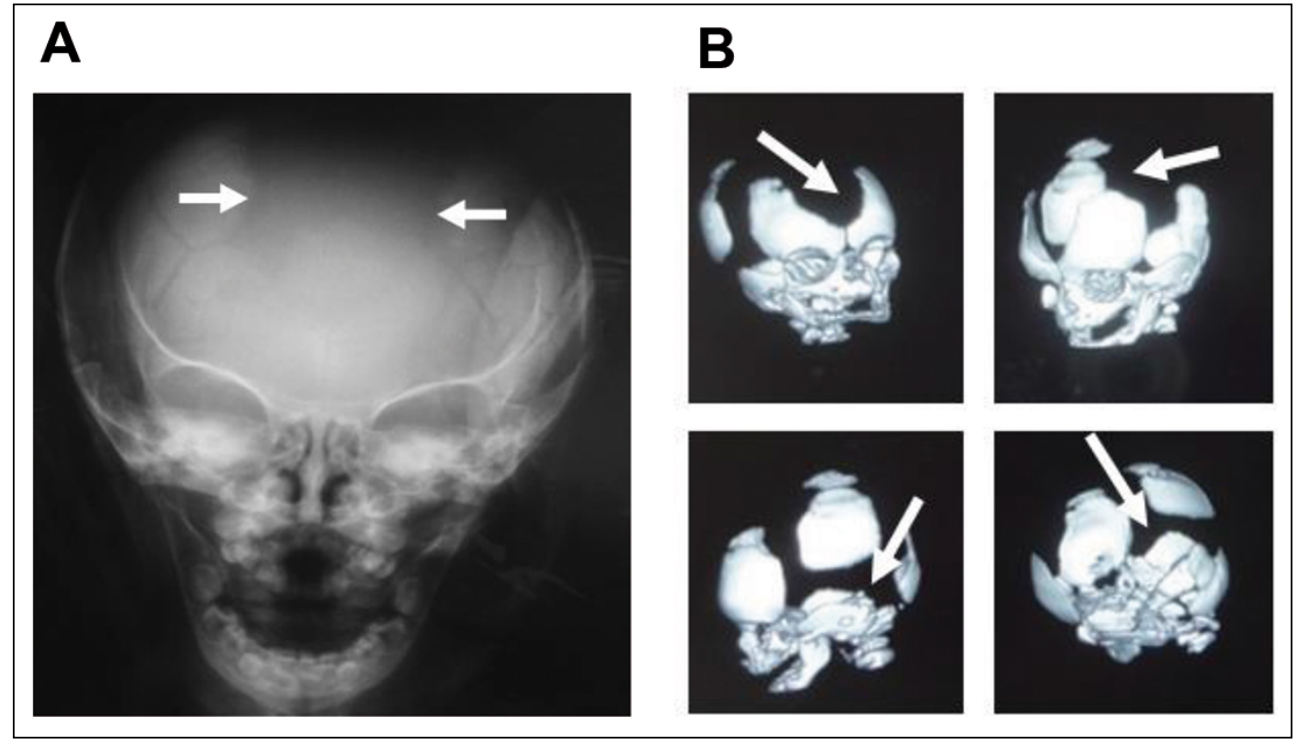

Figure 1. (A) Skull $x$-ray of the patient with cleidocranial dysplasia (1 month of birth): The arrows indicate the incomplete development of the cranial bones to the few days of born. (B) Computed tomography of the brain with three-dimensional reconstruction (1 month of birth): The arrows indicate alteration in the morphology of the cranial vault by absence in the process of calcification of the membranous structures of the frontal, parietal and temporal bones, what conditions a greater amplitude of the cranial sutures and of the fontanelles. rations were found at the time of examination or cleft palate (Figure 3E). The chest in the hood (Figure 4A), abdomen without pathological findings, limbs with hyperlaxity, palpable clavicles, without apparent abnormalities (Figures 4B and 4C), hands without bone or soft tissue alterations showed no brachydactyly or wide thumb (Figure 5A And 5B), flat foot (figure 5C) and genu valgo (figure 5D). No signs of apparent neurological deficit were found in the nervous system. No hearing evaluation was performed.

The molecular study for the complete sequencing of the RUNX2 gene reported that the patient is a carrier of the pathogenic variant c.674G $>A$ in the RUNX2 gene, which confirmed the diagnosis of CCD. This variant produces the change of the amino acid arginine by glutamine at position 225 of the polypeptide chain, affecting a highly conserved residue between species (p.Arg225Glun) ${ }^{17}$. This change has previously been described as a pathogenic mutation associated with cleidocranial dysplasia, in the databases of ClinVar-NCBI mutations and HGMD (Human Gene Mutation Database) with ID CM992614. This variant has also previously been described in the dbSNP database (NCBI) with ID rs104893991, with no frequency in the control population, where the database itself reports it with pathogenic clinical significance.

\section{Discussion}

The presence of this newborn with an absence of cranial bones drew our attention, due to its posibility of being a chromosomal alteration case with bone compromise. This clinical finding requires all the diagnostic help necessary to carry out a correct diagnosis

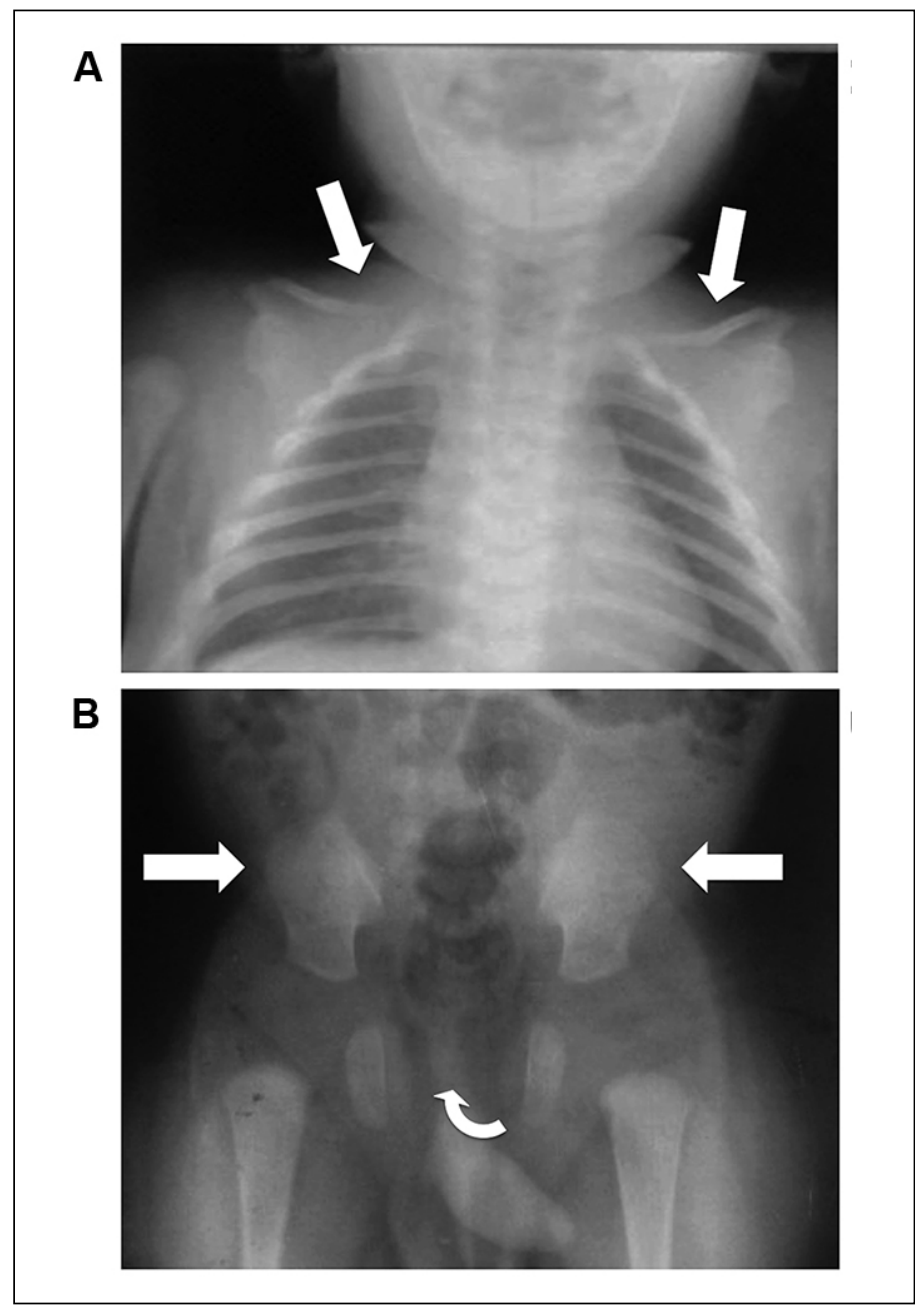

Figure 2. (A): Chest X-ray (2 months old): There is less development of the lateral third of clavicles, the somewhat hypoplastic scapulae. (B): Hip X-ray (4 months old): No ossification of the pubis, hypoplasia of iliac bones. 
Figure 3. Craniofacial and dental phenotype of the patient with cleidocranial dysplasia at 3 years of age. (A): hypertelorism with broad nasal bridge. (B) y (C): Depression of the bone table at the frontal bone level. (D): It is not possible to see depression of the bone table in the profile photo. (E): Dentures are observed in good condition, without anomalies.

Figure 4. (A): bell-shaped chest of the patient with cleidocranial dysplasia: Patient 3 years old with diagnosis of cleidocranial dysplasia. In the front view of the chest, the arrows indicate the widening of the ribs at the bottom. (B) $y$ (C): Palpable clavicles, with no clinical abnormalities at physical examination.
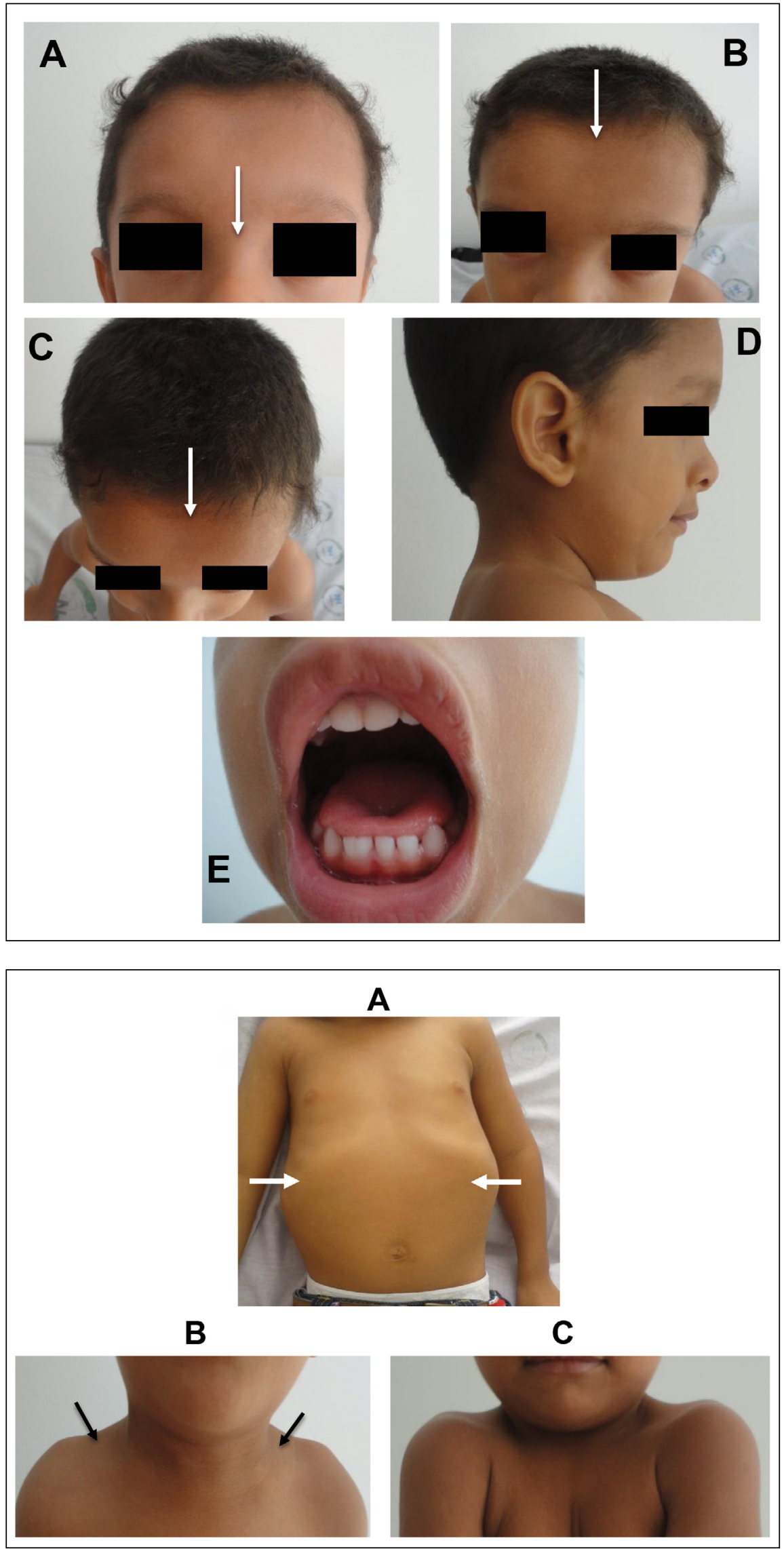


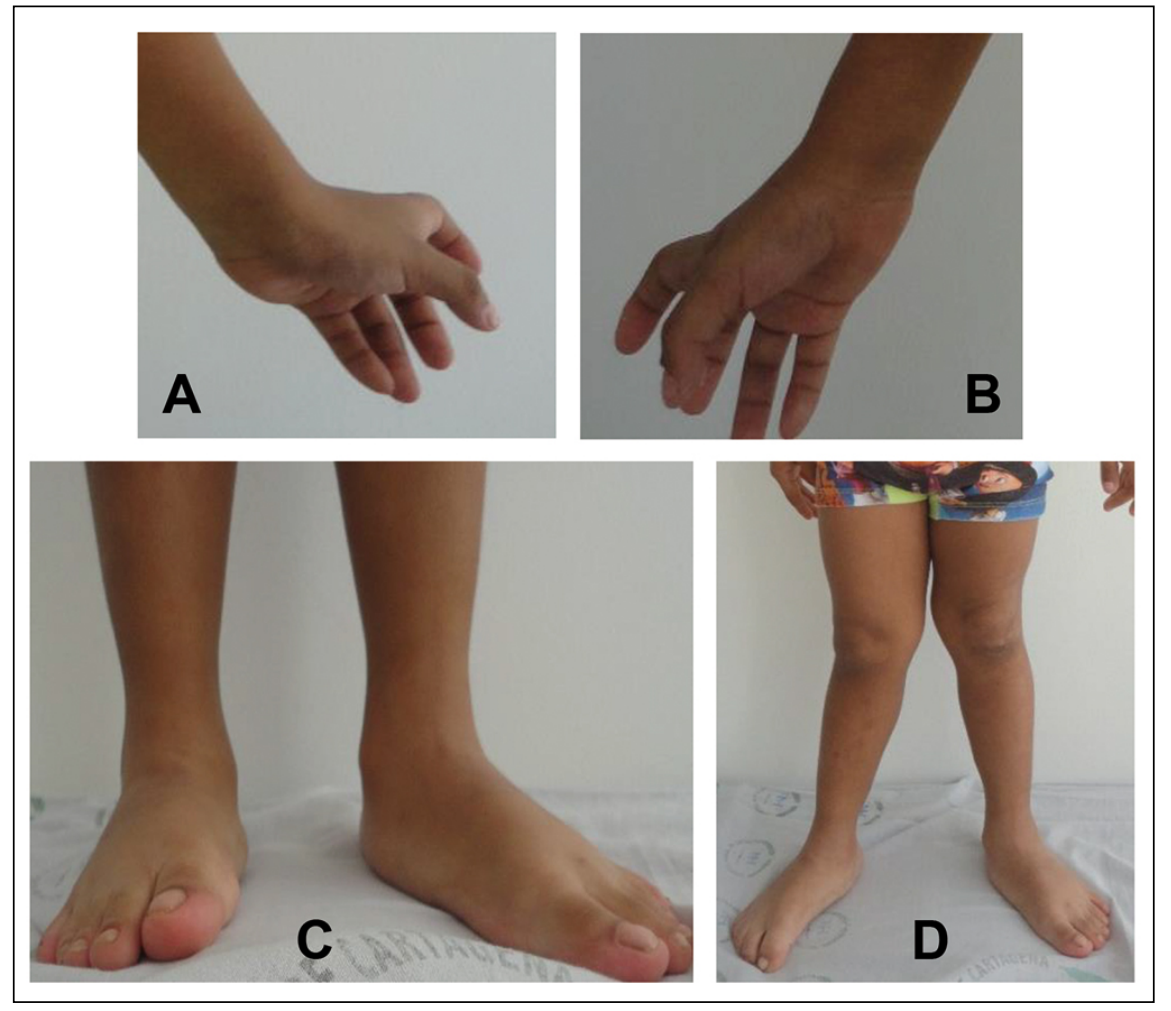

Figure 5. Lower and upper limbs characteristics. (A) y (B): No malformations are evident in upper limbs. (C): Flatfoot. (D): Genu valgum. from the moment of birth and thus determine with priority the need for a specific treatment ${ }^{18-20}$.

This clinical case was from the Service Provider Institution, where the following steps were taken in the clinical evaluation aimed at the etiology: A complete clinical history was done, with an emphasis on the family history looking for similar data that could suggest genetic causes of the problem to its Perinatal history; Detailed physical examination, with description of all the clinical findings of the patient; Assessment of anthropometric measures: weight, height and cephalic perimeter; An overall evaluation of the child was carried out as well; After the diagnostic impression approach, complementary examinations were performed as imaging studies, karyotype study in order to detect or rule out possible chromosomopathy and molecular study of the gene. Information was given to the family, diagnosis of the patient and the monitoring to be perfomed along with the professionals.

The clinical case presented in this research is very rare, but with common clinical signs ${ }^{19}$, for example, the patient presented an incomplete development of the cranial bones and wide nasal bridge with impression of ocular hypertelorism from the moment of birth, which called immediately the attention of the treating pediatrician at that moment ${ }^{21}$, so he requested and also he performed the studies according to the case, confirming the diagnosis of CCD.
This is one prove that shows how important is to perform a good physical examination at the moment of birth and also a monitoring of the neonatal evolution, in order to identify and to diagnose the pathology in a timely manner. The history of the patient did not report a family history that made suspicion of a hereditary anomaly, therefore everything points to a greater probability of a "De novo mutation".

There are many diagnostic criteria for this entity. Regarding this clinical case, there were certain abnormalities such as: supernumerary teeth with dental crowding and malocclusion; Abnormal denture, including delayed eruption of the secondary denture (which it was not evident since the patient was not old enough to perform this process naturally); Clavicular hypoplasia which resulted in narrow shoulders on the physical examination, although some hypoplasia is observed in the radiological study. There were no hand abnormalities such as brachydactyly, fine or thick fingers, or short thumbs. These individuals are more likely to have other skeletal/orthopedic problems, such as flat foot, genu valgus and scoliosis ${ }^{4}$, which were evidenced in the present patient.

This mutation results in haploinsufficiency of RUNX2 and poor cellular differentiation of osteoblastic precursors. The RUNX2 is expressed mainly by its neoplastic osteogenesis and its expression's increase has been associated with the etiology of sarcoma. Its 
overexpression in mice favour the development of T-cell lymphoma, osteopenia and multiple fractures, and in humans we could observe the development of craniosynostosis, maxillary hypoplasia and brachydactyly ${ }^{22}$.

The differential diagnosis includes mandibuloacral dysplasia, dental anomalies ${ }^{23}$, congenital clavicle pseudoarthrosis ${ }^{24}$, Yunis-Varon syndrome ${ }^{25}$, picnodisostosis $^{26}$, hypophosphatasia ${ }^{27}$, congenital hypothyroi$\operatorname{dism}^{28}$, among other entities that share common clinical features.

There is no specific treatment for skeletal problems, but these patients should have a periodic monitoring and evaluation by the trauma service, since within the problems previously mentioned, these patients are also more inclined to a shoulder dislocation and osteoarthritis in the adult stage ${ }^{21,29,30}$. At the same time, dental care should be important, requiring dental assessment from the outset ${ }^{30}$. It is important to protect their head and to avoid risks of trauma, since their cranial vault is not well ossified, as well as taking care of their respective otorhinolaryngological evaluation. The management of orofacial manifestations must be performed by a multidisciplinary team to obtain better results ${ }^{31}$.

Direct relatives have a 50\% inheritance of this mutation. Thus, it is recommended to carry out the genetic predictive study to all those relatives who are under risk.

As a conclusion, cleidocranial dysplasia is a rare disease in our country and environment. It comprehends a special, visible and noticeable clinical features, especially if a good physical examination is performed on the patient at an early stage. Most of the cases do not have an specific treatment, but surgical interventions could be done under certain circumstances, in order to correct physical anomalies and thus, to improve the quality of life of our patient.

\section{Ethical Responsibilities}

Human Beings and animals protection: Disclosure the authors state that the procedures were followed according to the Declaration of Helsinki and the World Medical Association regarding human experimentation developed for the medical community.

Data confidentiality: The authors state that they have followed the protocols of their Center and Local regulations on the publication of patient data.

Rights to privacy and informed consent: The authors have obtained the informed consent of the patients and/or subjects referred to in the article. This document is in the possession of the correspondence author.

\section{Financial Disclosure}

Vicerrectoría de Investigacion of the University of Cartagena, plan of strengthening and sustainability of the Group of Biochemistry and Disease

\section{Conflicts of Interest}

The authors declare that they have no conflict of interest with respect to this case report.

\section{Acknowledgements}

To the Faculty of Medicine of the University of Cartagena and Naval Hospital of Cartagena (Colombia) for facilitating access to information.

\section{References}

1. D’Alessandro G, Tagariello T, Piana G. Cleidocranial dysplasia: etiology and stomatognathic and craniofacial abnormalities. Minerva Stomatol. 2010; 59: 117-27.

2. Dhiman NK, Singh AK, Sharma NK, Jaiswara C. Cleidocranial dysplasia. National journal of maxillofacial surgery. 2014;5:206-8.

3. Wang J, Huang X, Lai C, Jiang K. Clinical spectrum of cleidocranial dysplasia in a family with twins. Pediatr Int. 2013;55:392-5.

4. Mendoza-Londono R, Lee B. Cleidocranial Dysplasia. In: Pagon RA, Adam MP, Ardinger HH, et al., (eds.).
GeneReviews(R). Seattle (WA)1993.

5. Bufalino A, Paranaíba LM, Gouvêa AF, Gueiros LA, Martelli-Júnior H, Junior JJ, et al. Cleidocranial dysplasia: oral features and genetic analysis of 11 patients. Oral Dis. 2012;18:184-90.

6. Mundlos S. Cleidocranial dysplasia: clinical and molecular genetics. J Med Genet. 1999;36:177-82.

7. Trigui M, Ayadi K, Elhassan MO, Zribi M, Chabchoub I, Keskes H. [Cleidocranial dysplasia: report of 2 cases and literature review]. Arch Pediatr. 2011;18:672-7.

8. da Cunha LF, Caetano IM, Dalitz F, Gonzaga CC, Mondelli J. Cleidocranial dysplasia case report: remodeling of teeth as aesthetic restorative treatment. Case
Rep Dent. 2014;2014: 901071

9. Singh S, Sharma S, Singh H, Wazir ND. Cleidocranial dysplasia: a case report illustrating diagnostic clinical and radiological findings. J Clin Diagn Res. 2014;8:ZD19-20.

10. Paul SA, Simon SS, Karthik AK, Chacko RK, Savitha S. A review of clinical and radiological features of cleidocranial dysplasia with a report of two cases and a dental treatment protocol. Journal of pharmacy \& bioallied sciences. 2015;7: S428-32.

11. Mahajan PS, Jayaram AP, Negi VC. Rare case of multiple aggressive vertebral hemangiomas. Journal of natural science, biology, and medicine. 2015;6:439-42.

12. Singh A, Goswami M, Pradhan G, Han 
MS, Choi JY, Kapoor S. Cleidocranial Dysplasia with Normal Clavicles: A Report of a Novel Genotype and a Review of Seven Previous Cases. Molecular syndromology. 2015;6:83-6.

13. Takenouchi T, Sato W, Torii C, Kosaki K. Progressive cognitive decline in an adult patient with cleidocranial dysplasia. Eur J Med Genet. 2014;57: 319-21.

14. Hermann NV, Hove HD, Jorgensen C, et al. Prenatal 3D ultrasound diagnostics in cleidocranial dysplasia. Fetal Diagn Ther. 2009;25:36-9.

15. Cooper SC, Flaitz CM, Johnston DA, Lee B, Hecht JT. A natural history of cleidocranial dysplasia. Am J Med Genet. 2001;104:1-6.

16. Lin WD, Lin SP, Wang CH, Tsai $Y$, Chen CP, Tsai FJ. RUNX2 mutations in Taiwanese patients with cleidocranial dysplasia. Genet Mol Biol. 2011;34:201-4.

17. den Dunnen JT, Antonarakis SE. Nomenclature for the description of human sequence variations. Human genetics. 2001;109:121-4.

18. González GE, Caruso PA, Small JE, Jyung RW, Troulis MJ, Curtin HD. Craniofacial and temporal bone $\mathrm{CT}$ findings in cleidocranial dysplasia. Pediatr Radiol. 2008;38:892-7.

19. Anthonappa RP, Yan-Hui F, King NM, Rabie AB, You-Qiang S. Novel complex disease allele mutations in cleidocranial dysplasia patients. J Oral Pathol Med. 2014;43:798-800.

20. Matsushita M, Kitoh H, Kaneko H, Mishima K, Itoh Y, Tokita Y, et al. A novel in-frame deletion of the RUNX2 gene causes a classic form of cleidocranial dysplasia. J Bone Miner Metab. 2014;32:96-9.

21. Shen Z, Zou CC, Yang RW, Zhao ZY. Cleidocranial dysplasia: report of 3 cases and literature review. Clin Pediatr (Phila). 2009; 48: 194-8.

22. Ortega RI, Obando FS. Displasia cleidocraneal: presentación de un caso. Universitas Médica. 2016; 57: 115-22.

23. Abanto J, Imparato JCP, Guedes-Pinto AC, Bönecker M. Anomalías dentarias de impacto estético en odontopediatría: Características y tratamiento. Revista Estomatológica Herediana. 2014; 22: 171.

24. Maldonado EH, Cock PR, de Ortopedia R. Pseudoartrosis congénita de la clavícula. Reporte de un caso. Rev Colomb Ortop Traumatol. 2006; 20: 65-7.
25. Elizondo-Dueñaz R, Rivera-Silva G, Abdala HM, López-Altamirano M, Martínez-Menchaca HR. Síndrome de Yunis-Varon. Gaceta Médica de México. 2012; 148: 81-2.

26. Velázquez LG. Picnodisostosis: Reporte de un caso. Revista Mexicana de Ortopedia Pediátrica. 2004; 6: 22-4.

27. Luna Ceballo E, Domínguez Pérez ME, Álvarez Núñez R. Hipofosfatasia: Presentación de un caso. Revista Cubana de Ortopedia y Traumatología. 2001; 15 : 87-9.

28. Pantoja Ludueña M, Mazzi Gonzales de Prada E, Paulsen Sandi K. Hipotiroidismo congénito. A propósito de un caso. Revista de la Sociedad Boliviana de Pediatría. 2002; 41: 11-4.

29. Vij R, Batra P, Vij H. Cleidocranial dysplasia: complete clinical, radiological and histological profiles. BMJ Case Rep. 2013; 2013.

30. Araya I, García M, Pantoja M, Espinoza A. Caso clínico-radiológico para diagnóstico. Rev Chil Pediatr. 2013; 84: 550-3.

31. Park TK, Vargervik K, Oberoi S. Orthodontic and surgical management of cleidocranial dysplasia. Korean J Orthod. 2013; 43: 248-60. 